\title{
Efecto del tiempo de electrodepósito de la fase sensibilizadora en DSSC empleando $\mathrm{TiO}_{2}$ como semiconductor
}

\section{Effect of the electrodeposition time of the sensitizing phase in DSSC using TiO2 as a semiconductor}

BALTAZAR-VERA, Juan Carlos $\dagger^{*}$, CAUDILLO-CAUDILlO, Luisa Marcela, SALAZARHERNÁNDEZ, Ma. Mercedes, ALVARADO-MONTALVO, Lucía Guadalupe, RODRÍGUEZRODRÍGUEZ, Carolina de Jesús y MIRANDA-AVILÉS, Raul

Universidad de Guanajuato, Departamento de Ingeniería en Minas, Metalurgia y Geología, Ex Hacienda San Matías S/N, colonia San Javier Guanajuato, Gto. CP 36020.

ID $1^{\text {er }}$ Autor: Juan Carlos, Baltazar-Vera / ORC ID: 0000-0056-59510-8300

ID $1^{\mathrm{er}}$ Coautor: Luisa Marcela, Caudillo-Caudillo

ID $2^{\text {do }}$ Coautor: Ma. Mercedes, Salazar-Hernández / ORC ID: 0000-0056-1828-64800

ID $3^{\text {er }}$ Coautor: Lucía Guadalupe, Alvarado-Montalvo / ORC ID: 0000-00428-6095-3200

ID $4^{\text {to }}$ Coautor: Carolina De Jesús, Rodríguez-Rodríguez / ORC ID: 0000-0056-9931-76100

ID $5^{\text {to }}$ Coautor: Raul, Miranda-Avilés / ORC ID: 0000-0014-0650-42700

DOI: $10.35429 /$ JTEN.2019.11.3.17.22

Recibido 03 de Junio, 2019; Aceptado 30 Septiembre, 2019

\section{Resumen}

En este trabajo se desarrolló una celda solar sensibilizada con colorante (DSSC) empleando Dióxido de Titanio como óxido metálico semiconductor; el colorante empleado fue amaranth, este colorante puede ser empleado para tal fin debido a los grupos cromóforos presentes en la molécula y a los grupos de anclaje afines al $\mathrm{TiO}_{2}$. Las pruebas realizadas fue la medición de respuesta fotovoltaica (corriente y voltaje) en celdas donde se varió el tiempo de electrodepósito del colorante a un voltaje de $1 \mathrm{~V}$; los resultados muestran que las eficiencias varían de acuerdo al tiempo registrándose valores de: $0.014 \%$ para un tiempo de $15 \mathrm{~s}, 0.009 \%$ a los $25 \mathrm{~s}, 0.18 \%$ a $\operatorname{los} 35 \mathrm{~s}$, $0.02 \%$ a los $45 \mathrm{~s}$ y $0.083 \%$ a los $55 \mathrm{~s}$, lo anterior muestra que el mejor tiempo de electro-depósito es de $35 \mathrm{~s}$ ya que en dicho parámetro, el sistema mostro la mejor eficiencia y estabilidad energética.

Celda solar sensibilizada con colorante, Semiconductor, Eficiencia

\begin{abstract}
In this work, a solar cell sensitized with dye (DSSC) was developed using Titanium Dioxide as semiconductor metal oxide; the dye used was amaranth, this dye can be used for this purpose due to the chromophoric groups present in the molecule and the anchor groups related to TiO2. The tests carried out were the measurement of photovoltaic response (current and voltage) in cells where the electrodeposition time of the dye was varied at a voltage of $1 \mathrm{~V}$; the results show that the efficiencies vary according to time, registering values of: $0.014 \%$ for a time of $15 \mathrm{~s}, 0.009 \%$ at $25 \mathrm{~s}, 0.18 \%$ at $35 \mathrm{~s}, 0.02 \%$ at $45 \mathrm{~s}$ and $0.083 \%$ at $55 \mathrm{~s}$, the above shows that the best electrodeposit time is $35 \mathrm{~s}$ due to in this parameter, the system showed the best efficiency and energy stability.
\end{abstract}

Solar cell sensitized wiyh dye, Semiconductor, Efficiency

Citación: BALTAZAR-VERA, Juan Carlos, CAUDILlO-CAUDILlO, Luisa Marcela, SALAZAR-HERNÁNDEZ, Ma. Mercedes, ALVARADO-MONTALVO, Lucía Guadalupe, RODRÍGUEZ-RODRÍGUEZ, Carolina de Jesús y MIRANDA-AVILÉS, Raul. Efecto del tiempo de electrodepósito de la fase sensibilizadora en DSSC empleando $\mathrm{TiO}_{2}$ como semiconductor. Revista de Ingeniería Tecnológica. 2019. 3-11: 17-22

\footnotetext{
* Correspondencia del Autor (Correo electrónico: jc.baltazarvera@ugto.mx)

$\dagger$ Investigador contribuyendo como primer autor.
} 


\section{Introducción}

El desarrollo de energías alternas es de vital importancia para el desarrollo sustentable de la humanidad, es por lo anterior que la energía fotovoltaica representa una alternativa importante en la contribución de este objetivo; de acuerdo a esto las celdas solares de silicio son las que predominan en dicho campo son las celdas de silicio con alrededor del $80 \%$ del total de celdas [1,2]. En la actualidad las celdas de silicio se encuentran en una eficiencia del $28 \%$.

Es por lo anteriormente escrito que la evolución de la tecnología fotovoltaica se ha desarrollado de manera importante, un ejemplo de esto son las celdas basadas en multifunciones de compuestos III-V, las cuales han logrado alcanzar eficiencias superiores al 30\% [3]; las celdas construidas en base a cobre, indio y selenio (CIS o CIGS cuando es añadido galio) y sus aleaciones, entre otras han alcanzado eficiencias superiores al $18.8 \%$ [4], de igual forma las celdas basadas en la unión CdTe/CdS han alcanzado eficiencias superiores a un $16 \%$ $[5,6]$.

Las celdas sensibilizadas con colorantes (DSSC) presentan las características de que pueden ser construidas fácilmente y con bajos costos; dichas celdas se encuentran constituidas por dos electrodos (cátodo y fotoánodo) en la cual un compuesto cromóforo funciona como antena fotoreceptora. El cátodo es un elemento translucido con propiedades conductoras de energía eléctrica, mientras que el fotoánodo se compone de una fase semiconductora por lo general a base de nanocristales de dióxido de titanio sobre el cual se deposita el compuesto fotorreceptor; el circuito se cierra al emplear un electrolito de unión líquida el cual contiene un par rédox que por lo general es $\mathrm{I}^{-} / \mathrm{I}^{-3}[7]$.

\section{Metodología}

\section{Elaboración del Fotoelectrodo}

Para la elaboración de este elemento se emplearon vidrios conductores del tipo óxido de estaño dopado con flúor (FTO, por sus siglas en inglés), con dimensiones de $2.5 \mathrm{~cm} \times 2.5 \mathrm{~cm}$ de área conductora, sobre el sustrato se deposita una capa semiconductora a partir de una solución de $\mathrm{TiO}_{2}-\mathrm{HCl} 10 \%$, el deposito se llevó a cabo por la técnica de electroforesis [8], empleando $3 \mathrm{~V} \mathrm{y}$ $20 \mathrm{~s}$ de tiempo de depósito.
Posteriormente se le proporciona al material un tratamiento térmico por $450^{\circ} \mathrm{C}$ por una hora con la finalidad de generar un anclaje estable entre la fase semiconductora y el FTO. Para el confinamiento de la fase sensibilizadora en el semiconductor se empleó una masa de 4.5 gr de colorante Amaranth en $60 \mathrm{ml}$ de acetonitrilo, dicho colorante fue depositado en la fase semiconductora por medio de electroforesis usando como contra electrodo acero inoxidable y separado del fotoelectrodo por una distancia de $10 \mathrm{~cm}$, se empleó un voltaje de $1 \mathrm{~V}$ y se varió el tiempo del proceso electroforético en $15 \mathrm{~s}, 25 \mathrm{~s}$, $35 \mathrm{~s}$, 45s y $55 \mathrm{~s}$. Posteriormente se lleva el fotoelectrodo a un tratamiento térmico de $160^{\circ} \mathrm{C}$ durante $1 \mathrm{hr}[9,10]$.

\section{Elaboración del Electrolito}

Para la solución electrolítica que contiene el par rédox se empleó una mezcla de I/LiI con relación 1:20 en $15 \mathrm{ml}$ de carbonato de propileno, dicha solución se debe mantener en un ambiente fresco y seco.

\section{Elaboración del Contraelectrodo}

Para la elaboración del contraelectrodo se preparó una solución $10 \mathrm{mM}$ de ácido hexacloroplatinico en 2 propanol, dicha solución fue esparcida mediante pipeta sobre la cara conductora de un FTO de dimensiones $2.5 \mathrm{~cm}$ x $2.5 \mathrm{~cm}$, posteriormente se le aplica un tratamiento térmico de $450^{\circ} \mathrm{C}$ durante una hora, lo anterior con la finalidad de asegurar el anclaje entre el platino y la fase conductora del FTO [11].

Ensamblado de la DSSC y prueba de respuesta energética

Para la construcción de la DSSC y desarrollo de la prueba de funcionamiento y respuesta energética se siguió la siguiente metodología:

1. Se confecciona un segmento de material translucido (hoja de transparencia) de aproximadamente $0.7 \mathrm{~mm}$ de espesor acorde al tamaño de la celda y enseguida se le hizo un orificio circular de $5 \mathrm{~mm}$ de diámetro.

2. Posteriormente se conectó la celda Grätzel al lado negativo del circuito anteriormente mencionado. 
3. En seguida se colocó el acetato en la celda (el cual funcionará como separación entre electrodos con un área definida de contacto), ambos previamente limpiados con alcohol etílico para eliminar impurezas.

4. A continuación, se le agregaron unas gotas del electrolito en la sección de contacto electrolítico, ya que ahí es donde se va a llevar a cabo la interacción de electrones.

5. Posteriormente se colocó el contra electrodo a base de platino, el cual está conectado a la parte positiva del circuito; y así finalmente se cierra el circuito.

6. Se enciende la lámpara, la cual va a proporcionó la luz incidente a la celda en un ángulo de $90^{\circ}$ y a una distancia aproximada de $15 \mathrm{~cm}$ (Ver figura 1).

7. Por último, para obtener los valores de voltaje y amperaje, los cuales son necesarios para la curva de descarga, se construye un circuito de resistencia variable con un rango de $0 \mathrm{~K}$ a $50 \mathrm{~K}$ acoplado a un medidor de Voltaje y un medidor de amperaje.

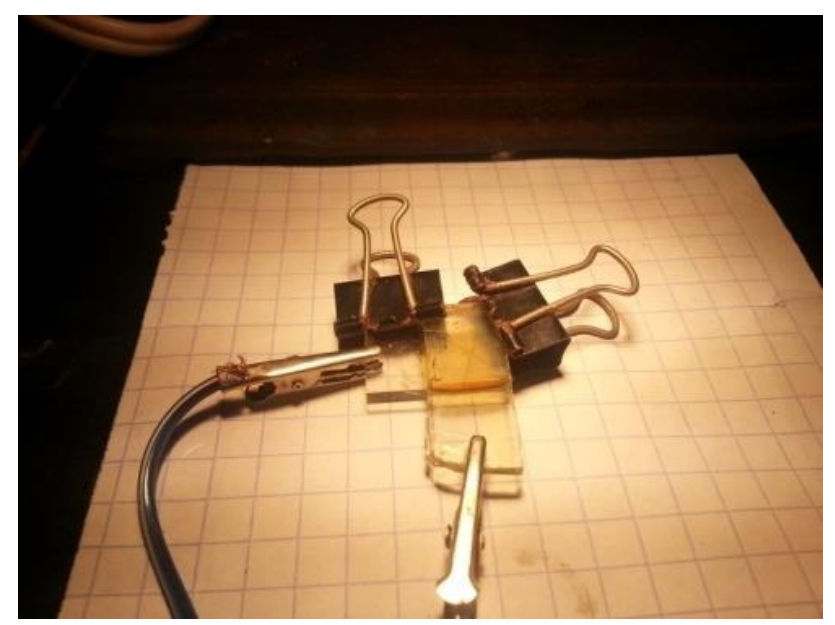

Figura 1 Ensamble y prueba energética de la DSSC

\section{Resultados}

\section{Respuesta energética}

En la figura 2 se muestra los resultados de respuesta energética de la DSSC empleando un tiempo de $15 \mathrm{~s}$ de proceso electroforético para el confinamiento de la antena fotorreceptora, en dicha figura se puede observar que en términos de la densidad de corriente (j en $\mu \mathrm{A} / \mathrm{cm}^{2}$ ) la celda opera en un rango de 0 a $9.55 \times 10^{-7}$ siendo este último valor la densidad de corriente a corto circuito.
En términos del fotopotencial (E en $\mathrm{mV}$ ) la celda opera en el rango de 0 a 21 siendo este último el potencial correspondiente a circuito abierto; realizando una inspección de la gráfica representada en la figura dos se puede observar que existe una relación con homogeneidad aceptable entre los parámetros involucrados lo cual es indicativo de estabilidad en el proceso fotoenergético de la celda.

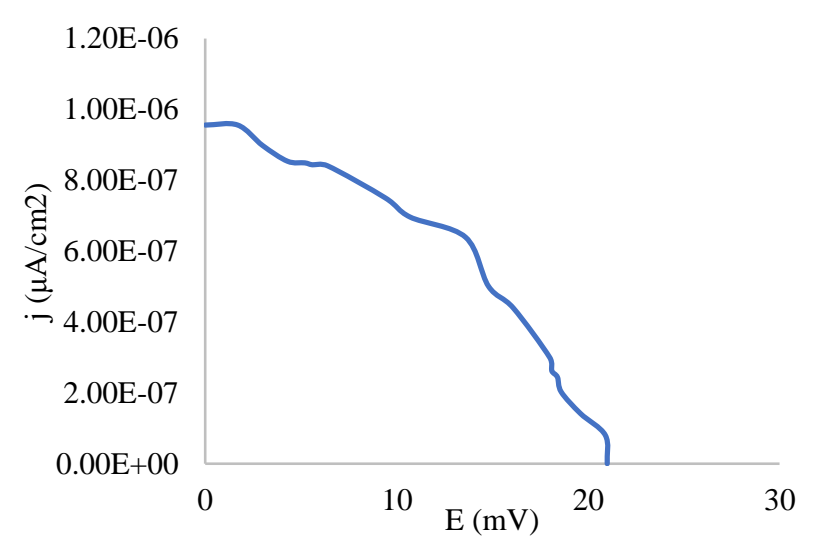

Figura 2 Respuesta energética (E vs j) para DSSC con un tiempo de $15 \mathrm{~s}$ de proceso electroforético para confinamiento del sensibilizador

En la figura 3 se observa los resultados de respuesta energética de la DSSC empleando un tiempo de $25 \mathrm{~s}$ de proceso electroforético para el depósito del sensibilizador en la fase semiconductora; en esta figura se puede dilucidar que, en términos de la densidad de corriente, la celda opera en un rango de 0 a 1.87 $\mathrm{x} 10^{-7}$ correspondiendo este último valor a la densidad de corriente a corto circuito.

En función del fotopotencial, la celda opera en el rango de 0 a 20 siendo este último el potencial correspondiente a circuito abierto; realizando una inspección de la gráfica representada en la figura 3 se puede inferir que la homogeneidad entre los parámetros involucrados es menor con respecto al caso anterior, mostrando una tendencia decreciente marcada entre los mismo, lo cual indica que puede existir menor estabilidad del proceso fotoenergético que en el caso anterior.
BALTAZAR-VERA, Juan Carlos, CAUDILLO-CAUDILLO, Luisa Marcela, SALAZAR-HERNÁNDEZ, Ma. Mercedes, ALVARADO-MONTALVO, Lucía Guadalupe, RODRÍGUEZ-RODRÍGUEZ, Carolina de Jesús y MIRANDAAVILÉS, Raul. Efecto del tiempo de electrodepósito de la fase sensibilizadora en DSSC empleando $\mathrm{TiO}_{2}$ como semiconductor. Revista de Ingeniería Tecnológica. 2019 


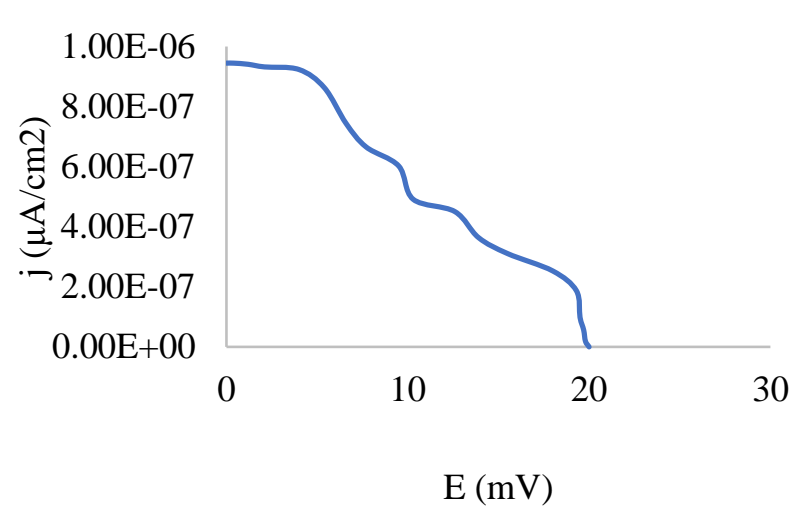

Figura 3 Respuesta energética (E vs j) para DSSC con un tiempo de $25 \mathrm{~s}$ de proceso electroforético para confinamiento del sensibilizador

En la figura 4 se muestran los resultados de respuesta energética de la DSSC empleando un tiempo de $35 \mathrm{~s}$ de proceso electroforético para el depósito del colorante en la fase semiconductora; en esta figura se puede observar que, en términos de la densidad de corriente, la celda opera en un rango de 0 a $6.0 \times 10^{-6}$ correspondiendo este último valor a la densidad de corriente a corto circuito. En función del fotopotencial, la celda opera en el rango de 0 a 48 siendo este último el potencial correspondiente a circuito abierto; llevando a cabo una inspección de la gráfica representada en la figura 4 se puede dilucidar que existe una homogeneidad aceptable entre los parámetros involucrados lo cual al igual que en el caso de la celda correspondiente a $15 \mathrm{~s}$, la estabilidad del proceso fotoenergético es posiblemente aceptable.

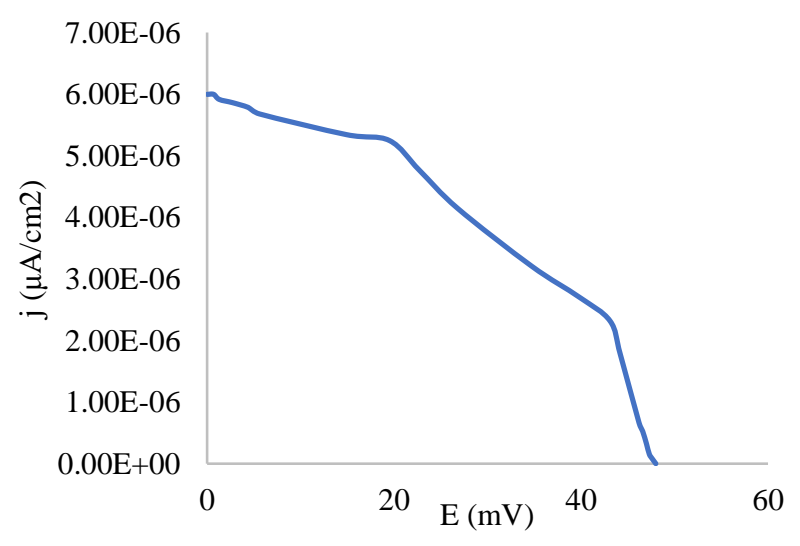

Figura 4 Respuesta energética (E vs j) para DSSC con un tiempo de $35 \mathrm{~s}$ de proceso electroforético para confinamiento del sensibilizador

En la figura 5 se representan los resultados de respuesta energética de la DSSC empleando un tiempo de $45 \mathrm{~s}$ de proceso electroforético para el depósito de la antena fotoreceptora en la fase semiconductora.
En esta figura se muestra que, en términos de la densidad de corriente, la celda opera en un rango de 0 a 4.4 x $10^{-7}$ correspondiendo este último valor a la densidad de corriente a corto circuito. En función del fotopotencial, la celda opera en el rango de 0 a 44.4 siendo este último el potencial correspondiente a circuito abierto; realizando cabo una inspección de la gráfica representada en la figura 5 se puede observar que existe una homogeneidad aceptable entre los parámetros involucrados lo cual al igual que en los casos de las celda correspondiente a $15 \mathrm{~s}$ y $35 \mathrm{~s}$, la estabilidad del proceso fotoenergético es posiblemente aceptable; en dicha figura se puede observar que existe un sostenimiento de los parámetros energéticos durante el proceso de prueba lo cual puede indicar un buen índice de regeneración del sensibilizador, lo cual es un aspecto importante en la estabilidad de la celda.

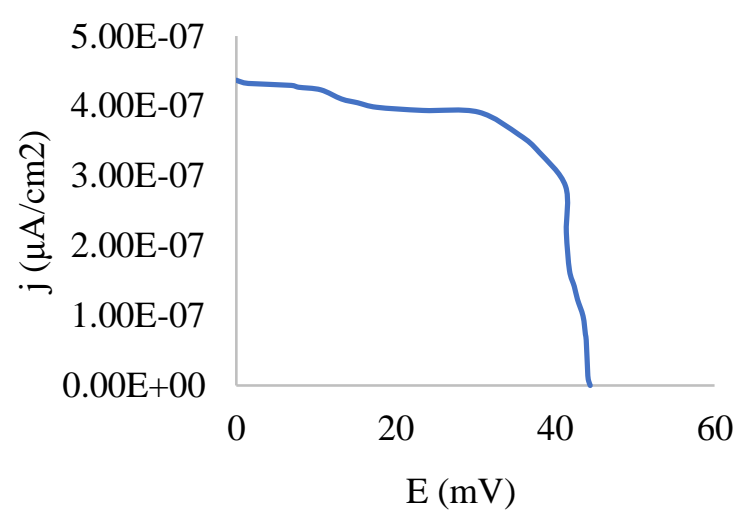

Figura 5 Respuesta energética (E vs j) para DSSC con un tiempo de $45 \mathrm{~s}$ de proceso electroforético para confinamiento del sensibilizador

En la figura 6 se muestran los resultados de respuesta energética de la DSSC empleando un tiempo de $55 \mathrm{~s}$ de proceso electroforético para el depósito de la antena fotoreceptora en la fase semiconductora; en esta figura se muestra que, en términos de la densidad de corriente, la celda opera en un rango de 0 a $1.93 \times 10^{-5}$ correspondiendo este último valor a la densidad de corriente a corto circuito.

En función del fotopotencial, la celda opera en el rango de 0 a 40 siendo este último el potencial correspondiente a circuito abierto; realizando cabo una inspección de la gráfica representada en la figura 6 se puede observar que la celda presenta un decaimiento energético pronunciado lo cual es indicativo de la inestabilidad del proceso de generación de fotocorriente. 


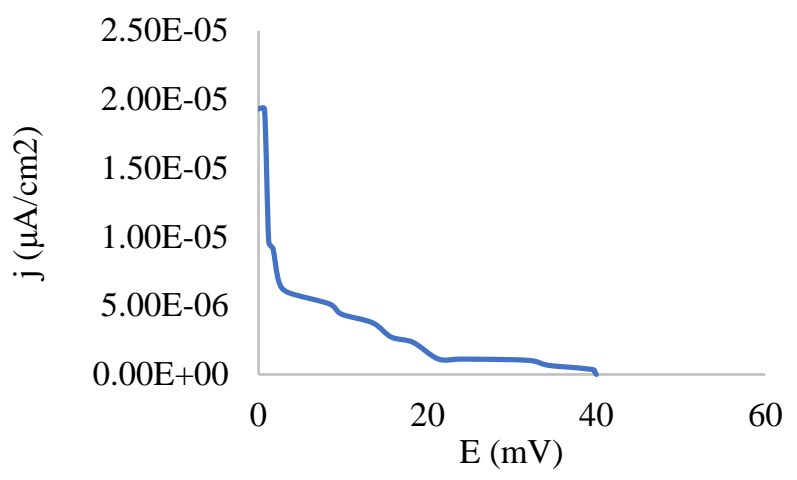

Figura 6 Respuesta energética (E vs j) para DSSC con un tiempo de $55 \mathrm{~s}$ de proceso electroforético para confinamiento del sensibilizador

\section{Eficiencia energética}

En la tabla 1 se muestran los datos de eficiencia energética a diferentes tiempos de proceso electroforético para el confinamiento del colorante, los datos de esta tabla muestran que los valores de eficiencia energética obtenidos son: $0.014 \%$ para un tiempo de $15 \mathrm{~s}, 0.009 \%$ a $\operatorname{los} 25 \mathrm{~s}, 0.18 \%$ a los $35 \mathrm{~s}, 0.02 \%$ a los $45 \mathrm{~s}$ y $0.083 \%$ a los $55 \mathrm{~s}$.

\begin{tabular}{|r|r|}
\hline \multicolumn{2}{|c|}{$\begin{array}{c}\text { Tiempo de proceso } \\
\text { electroforético para } \\
\text { el confinamiento del } \\
\text { sensibilizador (s) }\end{array}$} \\
\hline 15 & 0.14 \\
\hline 25 & 0.009 \\
\hline 35 & 0.18 \\
\hline 45 & 0.02 \\
\hline 55 & 0.083 \\
\hline
\end{tabular}

Tabla 1 Eficiencia energética correspondientes a diversos tiempos de proceso electroforético para confinamiento del sensibilizador

\section{Análisis de potencia energética de celda}

En la figura 7 se muestra el diagrama potencia voltaje (P-E) de la celda fotovoltaica que presentó una mayor eficiencia y estabilidad, la cual fue la de $35 \mathrm{~s}$ de proceso electroforético; En dicha figura se puede observar que la potencia máxima registrada es alrededor de 0.11 $\mathrm{mW} / \mathrm{cm}^{2}$. Así mismo en la gráfica se observa una estabilidad de los valores de potencia en un rango de voltaje de 19.5 a $43.1 \mathrm{mV}$, lo cual es indicativo de estabilidad energética de la celda.

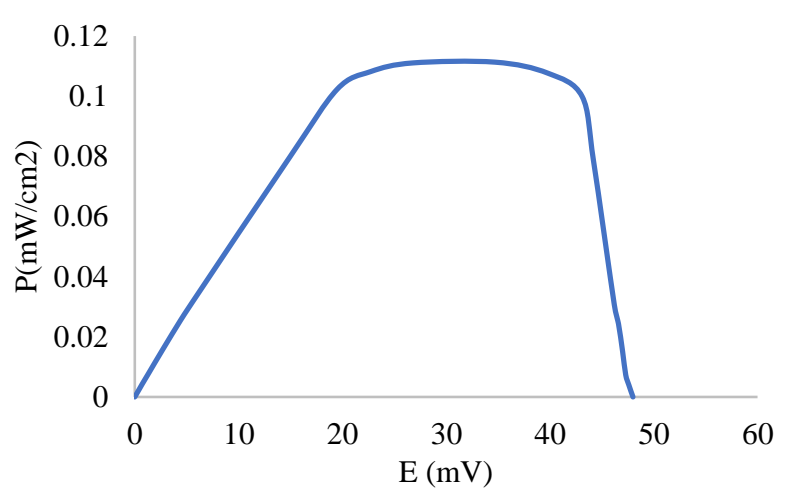

Figura 7 Respuesta energética (E vs P) para DSSC con un tiempo de $35 \mathrm{~s}$ de proceso electroforético para confinamiento del sensibilizador

En la figura 8 se muestra el diagrama potencia densidad de corriente $(\mathrm{P}-\mathrm{j})$ de la celda fotovoltaica que presentó una mayor eficiencia y estabilidad, la cual fue la de $35 \mathrm{~s}$ de proceso electroforético; En dicha figura se puede observar que al igual que en el caso anterior un rango de estabilidad de potencia se presenta a valores de densidad de corriente entre $2.7 \times 10^{-6} \mathrm{y}$ $4.4 \times 10^{-6}$, lo cual es indicativo de estabilidad energética de la celda.

\section{Conclusiones}

En este trabajo se muestran los resultados de respuesta energética de una celda solar sensibilizada con colorante variando el tiempo del proceso electroforético propio del confinamiento de la antena fotoreceptora en la fase semiconductora. En el estudio se puede observar que la celda que presento la eficiencia energética más elevada fue la celda con un tiempo de proceso de $35 \mathrm{~s}$, así mismo las DSSCs que presentaron características de una posible estabilidad energética fueron las correspondientes a $15 \mathrm{~s}, 25 \mathrm{~s}, 35 \mathrm{~s}$ y $45 \mathrm{~s}$ por lo cual se puede inferir que los mejores resultados se obtienen a los $35 \mathrm{~s}$ de proceso electroforético de depósito del colorante, lo anterior es alentador ya que se puede proseguir con las siguientes etapas de caracterización fisicoquímicas y energéticas del sistema con el objetivo de poder dilucidar los mecanismos de transferencia de energía de la celda y así poder proponer alternativas para el incremento de la eficiencia energética de la misma.

\section{Agradecimientos}

Los autores de este proyecto agradecen al proyecto UGTO-PTC-633 de PRODEP por el apoyo para la realización del mismo. 


\section{Referencias}

[1] M.A. Green, K. Emery, D.L. King, S. Igariand S. Warta Solar Cell Efficiency Tables (Version 19), Prog. Photovolt.Res. Appl., 10 5562 (2002).

[2] Jianhua Zhao, Recent Advances of HighEfficiency Single Crystalline Silicon Solar Cells in Processing Technologies and Substrate Materials, Solar Energy Materials\& Solar Cells 82 53-64 (2004).

[3] Masafumi Yamaguchi III-V Compound Multi-Junction Solar Cells: Present and Future, Solar Energy Materials \& Solar Cells, 75 261269 (2003).

[4] M.A. Green,J. Zhao, A. Wang, S.R. Wenham, Progress and Outlook for HighEfficiency Crystalline Silicon Solar Cells, Solar Energy Materials \& Solar Cells 65 9-16 (2001).

[5] X. Wu, J.C. Keane,R.G. Dhere, C. DeHart, D.S. Albin, A. Duda, T.A. Gessert, S. Asher, D.H. Levi, and P.Sheldon, 16.5\%-Efficient CdS/CdTe Polycrystalline Thin-Film Solar Cel, 17th European Photovoltaic Solar Energy Conference, Munich, Germany, 22-26October 2001.

[6] J. Pantoja Enríquez, X.Mathew, G.P. Hernández, U. Pal, C. Magan, D.R. Acosta, R. Guardian, J.A. Toledo, G.Contreras Puente, J.A. Chávez Carvayar CdTe/CdS, Solar Cellson Flexible MolybdenumSubstrates, Solar EnergyMaterials\& Solar Cells82 307-314 (2004).

[7] A. Hagfeldt y M. Grätzel, Chem. Rev. 95 (1995) 49.

[8] A. Fujishima, T.N. Rao y D.A. Tryk, J. Photochem. Photobiol.C: Photochem. Rev. 1 (2000) 1.

[9] A. Wahl y J. Augustynski, J. Phys. Chem. B 102 (1998) 7820.

[10] J.-H. Yum, S.-S.Kim, D.-Y. Kim y Y.-E. Sung, J. Photochem.Photobiol. A: Chem. 173 (2005) 1.
[11] D.N. Furllong, D.E. Yates y T.W. Healy, en 'Electrodes of Conductive Metallic Y. Xu y M.A.A. Schoonen, Am. Mineral. 85 (2000) 543. 